\title{
Temporomandibular eklem osteoartriti: olgu bildirimi
}

\section{Ülkem Aydın*}

Ağız, Diş ve Çene Radyolojisi Anabilim Dalı, Başkent Üniversitesi Diş Hekimliği Fakültesi, Ankara, Türkiye

\section{Özet}

TANITIM: Eklem şikayetleri ile birlikte radyograflarda mandibular kondillerden birinin küçük olması, temporomandibular eklemde (TME) osteoartrit veya diğer artritler nedeniyle oluşan kemik yıkımına bağlı olabilir. Çocukluk çağında geçirilen travma veya alınan radyoterapiye bağlı kondil hipoplazisi ile birlikte sekonder TME problemi de ayırıcı tanıda düşünülmelidir.

OLGU BiLdiRimi: Kırk altı yaşında kadın hasta çene ekleminde ağrı şikayeti ile kliniğimize başvurdu. Ekstraoral muayenede deviasyon, sağ tarafta krepitasyon şeklinde eklem sesi ve hafif ağrı, sol tarafta sublüksasyon tespit edildi. Ağız açmada kısıtlııı yoktu. Panoramik radyografta sağ mandibular kondilin kortikal tabakasında kayıp ve şekil bozukluğu tespit edildi. Bilgisayarlı tomografi incelemesi ve romatoloji konsültasyonu yapıldı. Hasta protetik tedavisini yaptırdıktan sonra şikayetleri ortadan kalktı. Hastaya TME osteoartrit tanısı koyuldu.

Sonuç: Eklem şikayetleri ile birlikte radyograflarda mandibular kondillerden birinde kemik değişiklikleri görülüyorsa, osteaoartrit, poliartritler ve dejeneratif değişiklikler gösteren hipoplazik kondil, ayırıcı tanıda yer almalıdır. Kesin tanıya varabilmek için klinik ve radyografik bulguların yanı sıra kesitsel görüntülerden yararlanılmalı ve hasta romatolojik yönden de değerlendirilmelidir.

AnAhtar Kelimeler: Çok tarayıcılı bilgisayarlı tomografi; mandibular kondil; osteoartrit; radyografi, panoramik; temporomandibüler eklem

KAYNAK GöStermeK İçin: Aydın Ü. Temporomandibular eklem osteoartriti: olgu bildirimi. Acta Odontol Turc 2015;32(1):26-30

YAYıN HAKKI: ( 2015 Aydın. Bu eserin yayın hakkı Creative Commons Attribution License ile ruhsatlandırılmıştır. Sınırsız kullanım, dağıtım ve her türlü ortamda çoğaltım, yazarlar ve kaynağın belirtilmesi kaydıyla serbesttir.

[Abstract in English is at the end of the manuscript]

\footnotetext{
Makale gönderiliş tarihi: 22 Şubat 2013; Yayına kabul tarihi: 11 Eylül 2013 *iletişim: Ülkem Aydın, Başkent Üniversitesi Diş Hekimliği Fakültesi, Ağız, Diş ve Çene Radyolojisi Anabilim Dalı, 11. Sokak, No: 26, Bahçelievler, Ankara, Türkiye;

e-posta: ulkem_aydin@yahoo.com
}

\section{Giriş}

Mandibular kondilin kemik morfolojisindeki değişiklikler çoğu zaman karşımıza ilk olarak panoramik radyograflarda çıkmaktadır. Mandibular kondil; panoramik radyograflarda ramus mandibulaya bir boyun kısmı ile bağlı olan, elips benzeri bir kemik doku şeklinde görülür. Kondilin şekli belirgin değişiklikler gösterir; üst kısmı düz, sivri, açılı, yuvarlak veya dışbükey olabilir. ${ }^{1,2}$ Kondillerin radyografik değerlendirmesinde kondil hipoplazi ve hiperplazisi, eklem yüzeylerinde düzleşme, kortikal tabaka altında skleroz, subkortikal kistler, erozyon, osteofitler, eklem faresi, şekil bozukluğu ve kemik ankilozu olup olmadığı incelenmelidir. ${ }^{3}$

Panoramik radyograflarda yukarıda sözü edilen değişikliklerin birçoğu izlenebilir. ${ }^{2,4}$ Diğer yandan, panoramik radyografi tekniğinde kondilin lateral kutbu kondil başı üzerine süperpoze olur ve görüntünün anterior kısmını oluşturur; radyografta kondilin tepesi olarak görülen yer ise aslında kondilin medial kutbudur. Bu teknikle alınan radyograflarda artiküler fossa da kondilin üst kısmına süperpoze olur. ${ }^{1,5}$ Panoramik radyograflar değerlendirilirken bu anatomik özelliklerin, süperpozisyonların, ışınların geliş açısının ve hasta pozisyonlandırmadaki hataların etkileri gözönüne alınmalıdır. ${ }^{6}$ Bilgisayarlı tomografi, eklemin kemik komponentlerinin üç boyutlu şekli ve iç yapısı ile ilgili olarak, konvansiyonel radyograflardan daha çok bilgi verir. Bunun nedenleri, bilgisayarlı tomografide başka anatomik oluşumların kondil üzerine süperpoze olmaması, ince kesitler alınabilmesi, farklı düzlemlerde inceleme yapılabilmesi ve üç boyutlu rekonstrüksiyon yapılabilmesidir. ${ }^{2}$

Kondillerde şekil ve büyüklük anomalilerinin nedenleri konjenital veya kazanıımış olabilir. Kraniyofasiyal malformasyonlar, çocukluk çağında geçirilen travma veya alınan radyoterapi, kondili etkileyen enfeksiyonlar kondilde büyüme ve gelişmeyi olumsuz etkileyebilir., 2,7, Buna ek olarak, temporomandibular eklem tutulumu olan artritler ve osteoartrit de kondillerde değişikliklere neden olabilir. 2,5,9

Bu makalede, panoramik radyografta sağ mandibular kondilde şekil bozukluğu ve kortikal tabakada kayıp tespit edilen olgu sunulmuş; olası etiyolojik faktörler, ayırıcı tanı, klinik ve radyografik bulgular ve tedavi planlaması tartışılmıştır. 


\section{Olgu Bildirimi}

Kırk altı yaşındaki kadın hasta çenesinde ağrı şikayeti ile Başkent Üniversitesi Diş Hekimliği Fakültesi'ne başvurdu. Anamnezde yaklaşık iki ay önce esneme sırasında çenesinden ses geldiğini ve bundan sonra bir farklılık hissettiğini belirtti ve bunu çenesinin çıktığı şeklinde yorumlamaktaydı. O dönemde özellikle geceleri sağ tarafına yattığında ağrı olduğunu, sabahları çenesinde ağrı olduğunu ve ağzını açmakta zorluk çektiğini belirtti. Hasta bir süre kas gevşetici kullanmış ve şikayetlerinin tam olarak geçmemesi nedeniyle başvurmuştu. Sistemik anamnezinde hastanın demir eksikliği anemisi olduğu ve bu nedenle antianemik (Tardyferon, Pierre Fabre) ve demir preparatı (Ferro-Sanol, Adeka) kullandığı, diyabet hastalığı nedeniyle de oral antidiyabetik (Amaryl, Aventis Farma) kullandığı öğrenildi. Ekstraoral muayenede sağ tarafta krepitasyon şeklinde eklem sesi, açma-kapatma sırasında deviasyon ve sol tarafta sublüksasyon tespit edildi; ağız açmada kısıtlılık yoktu. Fonksiyon muayenesi sırasında hasta hafif ağrı hissettiğini belirtti. İntraoral muayenede diş eksiklikleri ve iki dişte çürüksüz servikal lezyon gözlemlendi.

Panoramik radyografta (Resim 1) kondillerin asimetrik olduğu, sağ kondilin daha küçük ve ince olduğu ve kondil başında şekil bozukluğu bulunduğu gözlendi. Kondili çevreleyen kortikal tabaka izlenemedi. Sol taraf normal görünümdeydi.

Hastadan temporomandibular eklem bilgisayarlı tomografi (BT) tetkiki istendi. Başkent Üniversitesi Tıp Fakültesi Radyoloji Anabilim Dalında 0,75 kalınlıkta aksiyal kesit görüntüler alındı. Aksiyal kesitlerde sağ kondil başında kortikal konturun kaybolduğu ve spongioz tabakada kemik densitesinin düştüğü izlendi (Resim 2). Koronal kesitlerde sol temporomandibular eklemde, artiküler fossa, kondil ve kondil-fossa ilişkisi normaldi. Sağ tarafta ise kondil başında erozyona bağlı yükseklik kaybı ve eklem aralığında daralma tespit edildi (Resim 3). Sagital kesitte sağ kondil üst sınırında düzensizlik belirgindi (Resim 4). Tetkik alanına dahil diğer kemik yapılar normal olarak izlendi. Hasta romatoloji bölümünde konsülte edildi, yapılan tetkikler sonucunda CRP, sedimantasyon hızı ve romatoid faktör normal bulundu ve hastada romatolojik patoloji olmadığı tespit edildi.

Hastaya eklemde zorlama yaratacak hareketlerden kaçınması, protez yaptırması önerildi ve üç ay sonrası için kontrol randevusu verildi. Hastanın klinik ve radyografik olarak düzenli takibi planlandı. Akut şikayetlerinin fakültemize başvurusundan önce ortadan kalkmış olması nedeniyle ilaç reçete edilmedi ve şikayetlerinde artış olursa kontrol randevusunu beklemeden tekrar başvurması söylendi. Hastanın üç ay sonra yapılan ilk kontrolünde protezlerini yaptırmış olduğu ve protezlerini yaptırdıktan sonra eklem sesi ve ağrı şikayetlerinin kal-

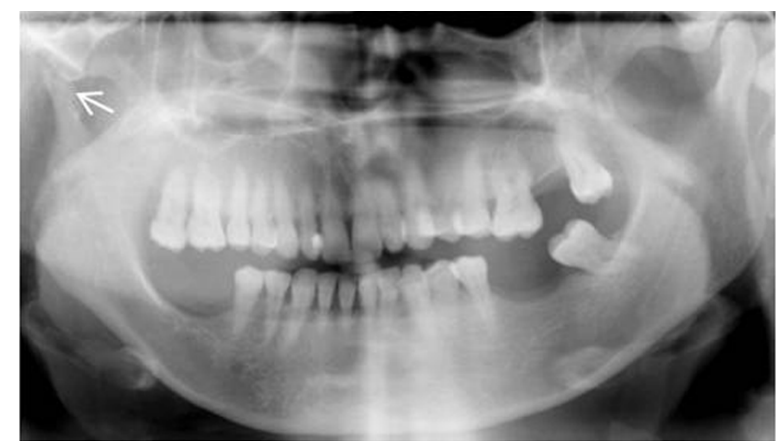

Resim 1. Panoramik radyografta kondillerde asimetri, sağ kondil başında şekil bozukluğu ve kortikal tabakada kayıp (ok)

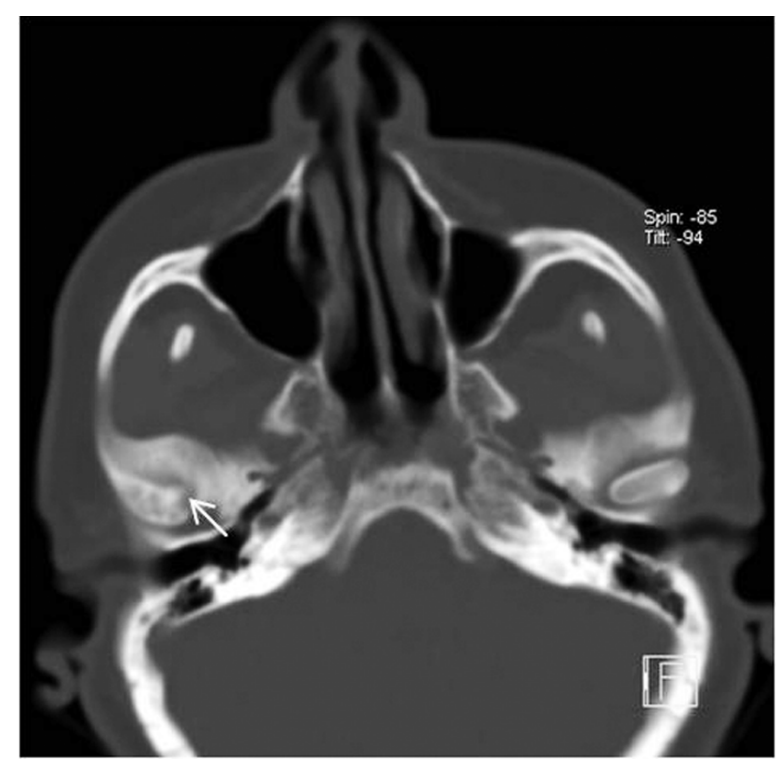

Resim 2. Aksiyal kesit BT görüntüsü; sağ kondil başında hipodens alanlar (subkortikal kistler; ok) ve kortikal erozyon

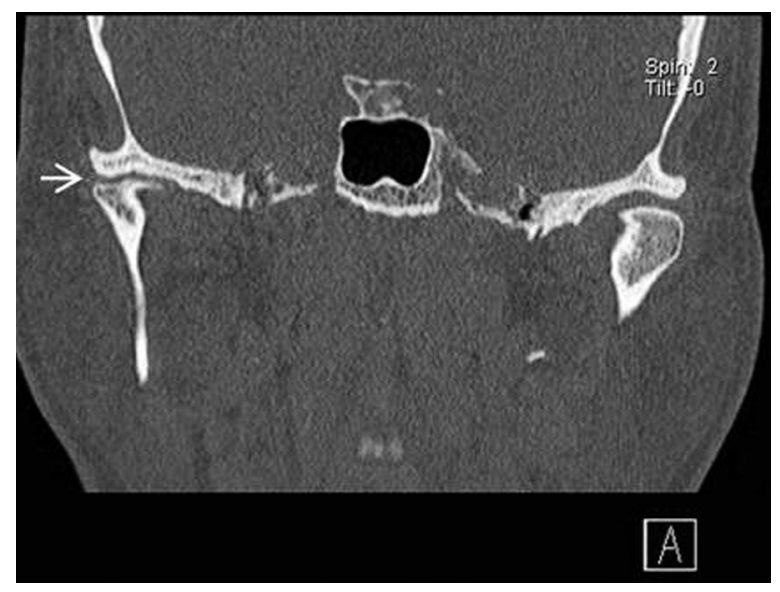

Resim 3. Koronal kesit BT görüntüsü; kondil başında erozyona bağlı yükseklik kaybı ve eklem aralığında daralma (ok)

madığı öğrenildi. Klinik muayenede, üst sabit, alt hareketli protezlerin uygun şekilde yapılmış olduğu, açmakapatma, lateral ve protrüziv hareketlerde ağrı olmadığı 


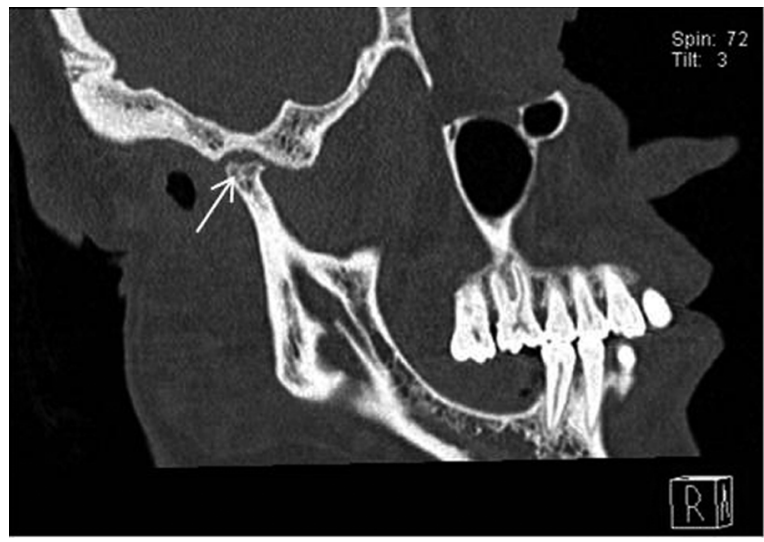

Resim 4. Sagital kesit BT görüntüsü; sağ kondil üst sınırında belirgin düzensizlik (ok), osteofit ve subkortikal kistler

tespit edildi. Panoramik radyografta kondilin görüntüsünde değişiklik gözlenmedi. Hastaya altı ay sonra kontrole gelmesi önerildi. Hasta altı ay sonra kontrole gelmediği için telefonla arandı ve şikayetleri ortadan kalktığı için gelmediği öğrenildi. Bir yıl sonra yine telefonla yapılan görüşmede şikayetlerinin tekrarlamadığı öğrenildi.

\section{TARTIŞMA}

Eklem şikayetleri ile birlikte radyograflarda mandibular kondillerden birinin küçük olması, sekonder temporomandibular eklem problemi ile birlikte kondil hipoplazisine bağlı olabileceği gibi, temporomandibular eklemde osteoartrit veya diğer artritler nedeniyle oluşan kemik yıkımına bağlı olarak da ortaya çıkabilir. ${ }^{2}$

Sunulan vakada büyüme-gelişme döneminde radyoterapi, kondilin büyümesini etkileyebilecek enfeksiyon ve belirgin bir travma hikayesi olmaması, konjenital ve kazanılmış kondil hipoplazisi kaynaklı temporomandibular eklem disfonksiyonunun elimine edilmesini sağlamıştır. Ekstraoral bulgularda kraniyofasiyal anomali bulgularına rastlanmaması, ramus ve mandibula gövdesinin normal büyüklükte olması da, konjenital ve kazanılmış kondil hipoplazisi kaynaklı temporomandibular eklem disfonksiyonu olmadığı görüşünü destekleyen özelliklerdi. ${ }^{2,7,8}$ Radyografik değerlendirmede de kortikal tabakada kayıp ve kemik kontüründe düzensizlik vardı. Ramus mandibula sağ tarafta sola göre daha dar görünmekle beraber panoramik radyograf incelendiğinde, sol tarafta dişler de sağa göre genişlemiş olduğundan, hastanın başını biraz çevirdiği ve geride kalan sol taraftaki oluşumların genişlemiş, diğer tarafın ise önde kalarak daralmış göründüğü sonucuna varıldı. Etkilenen tarafta mandibula gövdesinin yüksekliğinin de sol tarafa göre daha az olmasına karşın bu durumun diş kaybına bağlı mandibular kret rezorpsiyonunun bir sonucu olduğu düşünüldü. Radyografik ayırıcı tanıda da kondil hipoplazisi bu bulgulara dayanarak elimine edildi.
Romatoid artrit, psoriatik artrit, ankilozan spondilit, septik artrit ve gut hastalığında temporomandibular eklem tutulumu olabileceği ve bu hastalıkların kondilde erozyon, kontur düzensizliği ve kortikal tabakada kayba yol açabileceği uzun zamandır bilinmektedir. ${ }^{9-12}$ Bu hastalıklarda sistemik bulgular, enfeksiyon bulguları, diğer eklemlerin tutulması ve laboratuar testleri ayırıcı tanıyı sağlar. ${ }^{9}$ Sunulan olguda eklem bölgesinde lateral palpasyonda hassasiyet ve ıSı artışı tespit edilmemiş olması, sistemik bulguların yokluğu, konsültasyon sonucu yapılan romatolojik değerlendirme ve laboratuar testleri sonucunda hastada belirtilen hastalıkların bulunmadığı doğrulanmıştır. Özellikle romatoid artritte kondildeki değişikliklerin bilateral olması da radyografik ayıııcı tanıda yardımcıdır. ${ }^{13}$

Dejeneratif eklem hastalığı olarak da bilinen osteoartrit, temporomandibular eklemi de etkileyebilen bir eklem hastalığıdır. Osteoartritin en sık görülen nedeni ekleme gelen aşııı mekanik yüklerin eklemin işlevsel kapasitesini aşmasıdır. Hasta, genellikle mandibular hareketlerle artan tek taraflı eklem ağrısından şikayet eder. Ağrı kemik değişikliklerinin aktif olduğu dönemlerde olur ve bu dönemde hareket kısıtılıı̆ı ve krepitasyon olabilir. $2,5,13,14$

Osteoartrit teşhisi genellikle radyografik olarak doğrulanır. Radyograflarda, kondilin düzleştiği gözlenebilir; erozyon veya osteofit şeklinde yüzey düzensizlikleri izlenebilir. Kondil başında remodeling olabilir ve bölgesel ve yüzeysel olabileceği gibi kondil başının tamamında da gözlenebilir. Asemptomatik bireylerde de kondillerde bir miktar düzleşme olabileceği ancak erozyon ve osteofit gibi yüzey düzensizlikleri gözlenmediği belirtilmiştir.,215-17 Temporomandibular eklemde osteoartritle ilişkili kemik değişikliklerinin radyografik olarak görüntülenebilmesi için altı ay kadar geçmesi gerekebilir, bu nedenle de radyografik bulgular ilerlemiş vakalarda elde edilebilir. ${ }^{5}$ Erozyon, artiküler korteksin devamlıı̆ı̆ında bozulma olarak; şekil bozukluğu ise kondilin şeklinde düzleşmeye bağlanamayan bir normalden sapma olarak tanımlanmakta olup osteoartritin radyografik tanı kriterlerindendir. ${ }^{17}$ Sunulan vakada da sağ kondil başında kortikal tabakanın kaybolmuş ve spongioz tabakada kemik densitesinin düşmüş olması ve şekil bozukluğu osteoartritle uyumlu bulunmuştur.

Osteoartritte temporomandibular eklem şikayetleri ani veya kademeli olarak başlayabilir; bazen tekrarlayabileceği gibi tamamen ortadan kalkabilir veya uzun süreli olgularda şikayetler iyice azalabilir. ${ }^{13} \mathrm{Hastalığın} \mathrm{doğal}$ seyrinde, kemik değişiklikleri aynı kalırken klinik şikayetlerin ortadan kalkması ve hastalığın stabil hale gelmesi durumuna osteoartroz adı verilir. ${ }^{5}$ Dolayısı ile, osteoartroz olgularında da kondilde yukarıda sözü edilen, osteoartritle uyumlu radyografik değişiklikler izlenir. $5,13,18$ Sunulan vakada, hastanın klinik ve radyografik bulguları osteoartritle uyumlu olup şikayetlerinin büyük kısmı ortadan kalkmış olduğundan osteoartroz fazına geçiş döneminde kliniğimize müracaat ettiği anlaşıımaktadır. 
Osteoartritte majör etiyolojik faktör eklem yapılarının mekanik olarak fazla yüklenmesi olduğundan, tedavinin amacı da bu yükü ortadan kaldırmak olmalıdır. Bu amaçla gerektiği şekilde modifiye edilmiş stabilizasyon apareyleri kullanılabilir. Parafonksiyonel alışkanlıklar ortadan kaldırılmalı, çene hareketleri ağrısız sınırlar içinde yapılmalıdır. Hastalara yumuşak diyet önerilmeli, ağrı kesici ve antienflamatuar ilaç reçete edilmelidir. Ağrısız sınırlar içinde yapılacak pasif kas egzersizleri ve termoterapi uygulaması da önerilir. Osteoartrit kendini sınırlayan bir hastalık olduğundan hasta bu konuda da bilgilendirilmelidir. ${ }^{5,19}$ Cerrahi olmayan tedavi seçenekleri olumlu sonuç vermiyor ve şikayetler ciddi ve ısrarlı şekilde devam ediyorsa, hastada belirgin sıkıntılara neden olan ağrı ve/veya disfonksiyonun kaynağı temporomandibular eklem ise cerrahi tedaviler düşünülebilir. ${ }^{5,20} \mathrm{Te}$ davi amacıyla çeşitli apareylerin kullanımı önerilmekle beraber bu hastada uzun süreli dişsizlik hikayesi olduğundan öncelikle protetik tedavi gerekli görülmüştür. Hastanın şikayetlerinin protezlerini yaptırdıktan sonra tamamen geçmiş olması da osteoartroz fazına geçişe ek olarak stabil bir oklüzyonun sağlanması ile ekleme binen fazla yükün ortadan kalkmış olmasına bağlanabilir.

\section{Sonuç}

Eklem şikayetleri ile birlikte radyograflarda mandibular kondillerden birinin küçük olması durumunda ayırıcı tanıda osteaoartrit ve poliartritler düşünülmeli; kondil hipoplazisine neden olabilecek durumlar varsa dejeneratif değişiklikler gösteren hipoplazik kondil de ayırıcı tanıda yer almalıdır. Kesin tanıya varabilmek için klinik ve radyografik bulguların yanısıra sistemik şikayetler de gözönüne alınmalı ve ağız, diş ve çene radyolojisi uzmanı veya radyolog tarafından değerlendirilecek kesitsel görüntülerden yararlanılmalıdır.

Çıkar çatışması: Yazarlar bu çalışmayla ilgili herhangi bir çıkar çatışmalarının bulunmadığını bildirmişılerdir.

\section{KAYNAKLAR}

1. Oliveira C, Bernardo RT, Capelozza AL. Mandibular condyle morphology on panoramic radiographs of asymptomatic temporomandibular joints. Int J Dent 2009;8:114-8.

2. Petrikowski G. Diagnostic imaging of the temporomandibular joint. White SC, Phaorah MJ, eds. Oral radiology: Principles and interpretation. St. Louis: Mosby; 2009. p.473-505.

3. Ahmad M, Hollender L, Anderson Q, Kartha K, Ohrbach R, Truelove $\mathrm{EL}$, et al. Research diagnostic criteria for temporomandibular disorders (RDC/TMD): development of image analysis criteria and examiner reliability for image analysis. Oral Surg Oral Med Oral Pathol Oral Radiol Endod 2009;107:844-60.

4. Winocur E, Reiter S, Krichmer M, Kaffe I. Classifying degenerative joint disease by the RDC/TMD and by panoramic imaging: a retrospective analysis. J Oral Rehabil 2010;37:171-7.

5. Okeson JP. Management of temporomandibular disorders and occIusion. 6th edn. St. Louis: Mosby; 2008.
6. Honey OB, Scarfe WC, Hilgers MJ, Klueber K, Silveira AM, Haskell BS, et al. Accuracy of cone-beam computed tomography imaging of the temporomandibular joint: comparisons with panoramic radiology and linear tomography. Am J Orthod Dentofacial Orthop 2007;132:429-38.

7. Kaneyama K, Segami N, Hatta T. Congenital deformities and developmental abnormalities of the mandibular condyle in the temporomandibular joint. Congenit Anom (Kyoto) 2008;48:118-25.

8. Pirttiniemi P, Peltomäki T, Müller L, Luder HU. Abnormal mandibular growth and the condylar cartilage. Eur J Orthod 2009;31:1-11.

9. Helenius LM, Tervahartiala P, Helenius I, Al-Sukhun J, Kivisaari L, Suuronen R, et al. Clinical, radiographic and MRI findings of the temporomandibular joint in patients with different rheumatic diseases. Int $\mathrm{J}$ Oral Maxillofac Surg 2006;35:983-9.

10. Davidson C, Wojtulewski JA, Bacon PA, Winstock D. Temporo-mandibular joint disease in ankylosing spondylitis. Ann Rheum Dis 1975;34:87-91.

11. Goodwill CJ, Steggles BG. Destruction of the temporo-mandibular joints in rheumatoid arthritis. Ann Rheum Dis 1966;25:133-6.

12. Strobl H, Emshoff R, Kreczy A. Calcium pyrophosphate dihydrate crystal deposition disease of the temporomandibular joint. Oral Surg Oral Med Oral Pathol Oral Radiol Endod 1998;85:349-51.

13. Ogus $\mathrm{H}$. Degenerative disease of the temporomandibular joint and pain-dysfunction syndrome. J R Soc Med 1978;71:748-54.

14. Bermejo-Fenoll A, Sáez-Yuguero R. Differential diagnosis of temporomandibular joint disorders (TMD). Med Oral Patol Oral Cir Bucal 2005;10:468-9.

15. Badel T, Marotti M, Šimunković SK, Keros J, Kern J, Krolo I. Radiological characteristics of osteoarthritis of temporomandibular joint without disc displacement. Period Biol 2009;111:289-92.

16. Cevidanes LH, Hajati AK, Paniagua B, Lim PF, Walker DG, Palconet $\mathrm{G}$, et al. Quantification of condylar resorption in temporomandibular joint osteoarthritis. Oral Surg Oral Med Oral Pathol Oral Radiol Endod 2010;110:110-7.

17. Krisjane Z, Urtane I, Krumina G, Neimane L, Ragovska I. The prevalence of TMJ osteoarthritis in asymptomatic patients with dentofacial deformities: a cone-beam CT study. Int $\mathrm{J}$ Oral Maxillofac Surg 2012;41:690-5

18. Schmitter M, Essig M, Seneadza V, Balke Z, Schröder J, Rammelsberg P. Prevalence of clinical and radiographic signs of osteoarthrosis of the temporomandibular joint in an older persons community. Dentomaxillofac Radiol 2010;39:231-4.

19. Machon V, Hirjak D, Lukas J. Therapy of the osteoarthritis of the temporomandibular joint. J Craniomaxillofac Surg 2011;39:127-30.

20. Dimitroulis $G$. The role of surgery in the management of disorders of the temporomandibular joint: a critical review of the literature. Part 2. Int J Oral Maxillofac Surg 2005;34:231-7.

\section{Temporomandibular joint osteoarthritis: a case report}

\section{Abstract}

INTRODUCTION: Unilateral reduction in condylar size together with temporomandibular joint (TMJ) symptoms can be due to bone destruction as a result of TMJ osteoarthritis or other arthrides. Condylar hypoplasia due to childhood trauma or radiotherapy together with secondary TMJ problem should also be considered in the differential diagnosis.

CASE RePORT: Fourty six-year-old female patient attended with the complaint of TMJ pain. Extraoral examination revealed deviation, crepitus and mild pain on the right TMJ and subluxation on the left side. Range of motion was 
within normal limits. Cortical bone loss and deviation in form were detected on panoramic radiographs. Computed tomography examination and rheumatologic consultation was made. The complaints of the patient disappeared after prosthetic restoration. The patient was diagnosed with TMJ osteoarthritis.

Conclusion: Osteoarthritis, poliarthrides, and hypoplastic condyle demonstrating degenerative changes should be included in the differential diagnosis when condylar morphologic changes on radiographs accompany clinical TMJ symptoms. Besides clinical and radiographic findings, cross-sectional imaging techniques and rheumatological asessment should be used for definitive diagnosis.

KeYWORDS: Mandibular condyle; multidetector computed tomography; osteoarthritis; radiography, panoramic; temporomandibular joint 